\title{
Luck and Good Fortune in the Eudemian Ethics
}

Kent Johnson

Recently there has been some discussion of Aristotle's treatment of good fortune (Evitu $\chi^{i} \alpha$ ) in the penultimate chapter of the Eudemian Ethics. ${ }^{1}$ There are two claims about this chapter I wish to challenge. One maintains that the use of the word $\tau$ í $\eta$ (usually translated as 'luck' or 'chance') in the $E E$ is 'quite different' from Aristotle's theoretical discussion of luck, found in the Physics (Woods 1992, 67). The other claim is that good fortune is a subspecies of luck (Kenny 1992, ch. 5, esp. 71 and 75). In challenging these two views, I hope to develop an account of Aristotle's true intent in this chapter. In the first part of this article I consider the notion of luck as it is presented in the Physics and then argue that the discussion of luck in the $E E$ accords with this. In the second part I argue that by the end of his discussion of good fortune in the $E E$, Aristotle does not consider good fortune to be any kind of luck at all.

\section{Túx $\eta$ in the Physics and the Eudemian Ethics}

Woods 1992, 166 denies that the use of 'luck' ( $\tau \dot{x} x \eta$ in the $E E$ agrees with its

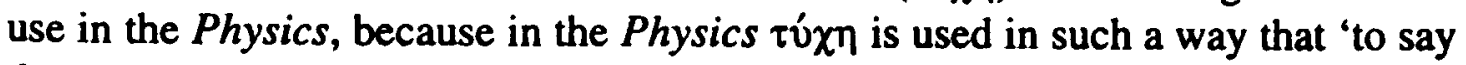
that something occurred by chance will not be to give an explanation, but to deny that a general explanation is available'. Thus, there is 'no incompatibility between something's occurring by chance and its being caused', since chance is not a cause distinct from the four real causes (Woods 1992, 167). Instead, 'chance occurrences have the feature that they fall under no law that holds universally or for the most part under the description under which they are correctly said to occur by chance, though they will have some explanation under another description' (166). In contrast, in the $E E$, Aristotle clearly asserts that 'it is necessary for luck to exist and to be a cause' (1247b3). Yet, in spite of appearances, I believe that close examination of the relevant passages of the Physics and the $E E$ shows that Aristotle does not use $\tau \dot{x} x \eta$ in different ways in the two works.

Túx in the Physics

The account of luck that emerges in the $E E$ seems to be underpinned by the theoretical discussion of luck found in the Physics and Metaphysics, or so I shall

\footnotetext{
' Kenny 1992, Mills 1981 and 1983, Pakaluk 1992, White 1992, Woods 1992.

I would like to thank Kelly Rogers and Ellen Haring, both of whom read several drafts of this article, and made many helpful suggestions. Heather Damron also helped me to see the importance of understanding Aristotle's theory in terms of moral bad luck. A general debt of thanks is owed to Anne Groton for her superb instruction in Greek.
} 
argue. That is, Aristotle's general beliefs about luck have an interesting influence on a particular subspecies of luck, namely, luck as it occurs in the moral sphere. I will argue that his theoretical beliefs about luck lead him to deny that many morally relevant cases of good fortune ( $\varepsilon \dot{v} \tau x i$ ) are due to luck. If this is right, then in order to see what morally relevant features of a person's life Aristotle will be forced to rule in or to rule out of the scope of luck, we need first to look briefly at his theoretical treatment of $\tau \dot{v} \chi \eta$, the details of which are found in Physics ii 5.

For reasons that will become clear shortly, it will be helpful to remember the following characteristics that Aristotle ascribes to luck in his theoretical account. Luck is:

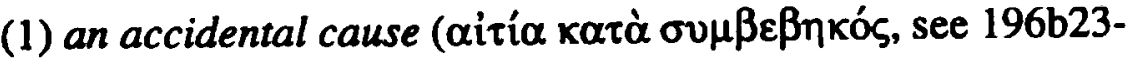
28,197 a5-6, 12-14, 32-35, 198a5-7)

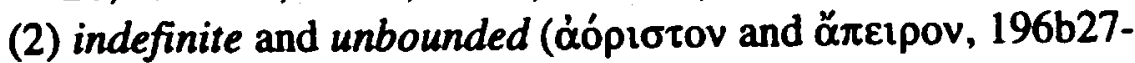
29, 197a8-10, 14-17, 20-21, 198a1-5)

(3) unaccountable for by reason ( $\pi \alpha \rho \alpha ́ \lambda$ oyov, 197a10, 18-20). In the sequel, I will suggest that luck's being an accidental cause entails that luck is relative to a description. I will also suggest that luck's being indefinite and unbounded means that (a) there may be many appropriate descriptions of a lucky event, and (b) it may be unclear whether a particular description is such that the event described is rightly said to be lucky: the description could be 'too near' the actual cause to be lucky, or 'too far away' to relate the cause and effect.

In Physics ii 5.197a5-6 Aristotle defines luck as, 'an accidental cause in the sphere of those actions for the sake of something which involve choice' (Solomon trans. in Barnes 1984). I take this to be Aristotle's official definition, since in Metaphysics 1065a26-b4, where he briefly sketches what luck is, his definition is virtually identical to this one, and the sketch repeats the main points of his theory of luck in the Physics (cf. 1013b34-1014a6, 1025a14-b1, 1026b1-7, and 1064b15-1065b4). Although this definition is somewhat murky, taken in context it reveals several things. Most importantly, it indicates that luck is an accidental cause. ${ }^{2}$ And since Aristotle regards a cause in the unqualified sense as something that holds always or for the most part, we know that unlike the four causes outlined in Phys. ii 3, luck is not a cause in the unqualified sense. Rather, whether or not an event is said to occur by luck is relative to the description of the event. Aristotle illustrates this with the example of a house built by a man who is both a flute player and a house builder. Since the flute player is the house builder, it is fair to say that the flute player built the house. This makes it the case that accidentally a flute player is the cause of the house's being built, whereas the

2 A more thorough discussion of luck would stress the importance of luck's being in the sphere of those actions for the sake of something involving choice, because this feature of luck is what differentiates it from spontaneity tò aviró $\mu$ zov, which includes not only cases of luck, but also cases

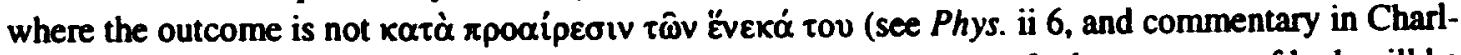
ton 1970, 109-111). Since I am concerned with moral luck, the range of relevant cases of luck will be

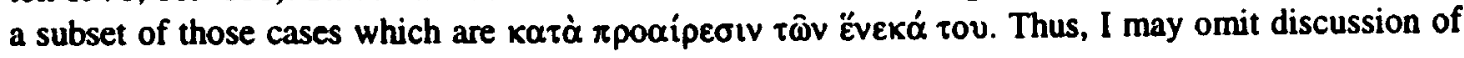
this important phrase. 
cause without qualification is a house builder (197a13-15). The flute player meets the condition for being an accidental cause of the house, since it does not hold always or for the most part that flute players (are able to) build houses. Thus, it is by luck that the flute player is able to build the house. As a second example, consider the case mentioned at 196b33-197a5, where A goes into the agora, and just happens to meet $B$, who owes him money. This is a case of luck only if $A$ is not aware that $B$ will be in the agora when he goes there. Descriptions of the event such as 'A met B in the agora and collected money from him' do not force us to assign luck as the cause of the event. The event involves luck only if its description makes it clear that it contains a sequence of events such that (1) one event is supposed to be the $\alpha i \tau i \alpha$ (in some sense) of another event, and (2) things of the sort falling under the description of the cause do not (necessarily) always or for the most part bring about things falling under the description of the effect.

Although Aristotle regards luck as an accidental cause, he is careful to qualify his definition by adding that not just any two events can be related as accidental

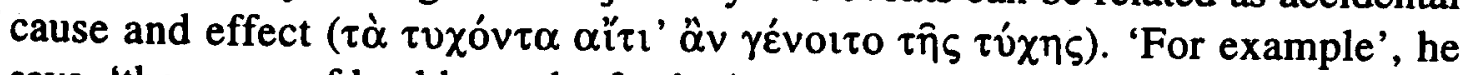
says, 'the cause of health can be fresh air or sun-heat, but not having had a haircut' (197a23-24). Some accidental causes, he says elsewhere, are 'nearer' or 'farther' away than others (195b1-3). ${ }^{3}$ It would be hard to give a clear and precise account of just what it is that makes two events sufficiently 'near' one another for one to be an accidental cause of the other. Thus Aristotle calls luck 'indefinite' (áóplotov, e.g., 196b27-28, 197a8-10, 20-21). Nonetheless, he holds that there

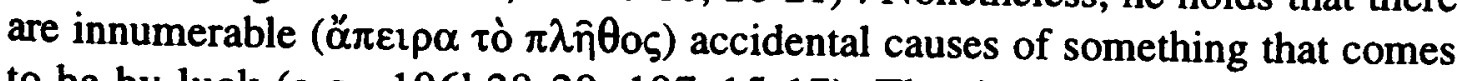
to be by luck (e.g., 196b28-29, 197a15-17). That is, there are innumerable descriptions of an event such that it can correctly be said that the event occurred by luck. Since any events that can be appropriately described as an accidental cause do not hold always or for the most part, and are not the sort of thing that have some rational organized basis, and since these accidental causes in this context are identical with luck, luck is said to be unaccountable ( $\pi \alpha \rho \alpha \lambda_{0} \sigma o v$, 197a18; cf. also Meta. 1065a33-34). ${ }^{4}$

It should be noted that Aristotle's account of luck seems to be connected with some of his other metaphysical theories. In particular, as Freeland 1992 and Judson 1992 have argued, the notion of accidental causation can be explained in terms of the four real causes and Aristotle's notion of accidental unities, or, as

\footnotetext{
${ }^{3}$ Note that even this description could be amended so as to constitute a case of accidental causation: if the person had discussed his illness with a doctor while at the barbershop, then the two events might be said to be related as accidental cause and effect. These additional details are an addition to Aristotle's description of the case, though, and I think that this provides further support for the claim that whether an event occurs by luck depends on the description of the case. In our new description of the case, having a haircut accidentally caused one to chat with the doctor, and chatting with the doctor caused one to get well (because the doctor's recommendations were followed). (This example is due to a referee for this journal.)

${ }^{4}$ Lennox 1982, 225-235 argues that an event is not caused by luck in virtue of the fact that the accidental cause produces the effect neither always nor for the most part.
} 
Matthews 1992 calls these latter things, 'kooky objects'. An example of a kooky object would be the house-builder who is also a flute-player (the house-builder

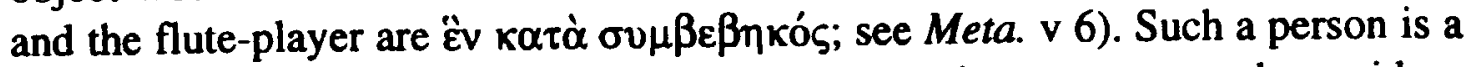
kooky object because he is 'an object whose very existence rests on the accidental presence, or compresence, of some feature, or features, in a substance'. ${ }^{5}$ When we extend the theory to include events as well as objects, we can see how the theory of kooky objects can help to explain accidental causation. First, there is some feature of the object or event that acts as a genuine cause, in Aristotle's sense, of the effect in question (or the feature is the genuine effect of some cause). ${ }^{6} \mathrm{Sec}$ ond, there is also some other feature of the object, that is irrelevant to the particular causal relation the object is involved in, and at least one of these two features is accidental to the object. Together, these two features that are present in the object make up a kooky object. There is a case of accidental causation when the irrelevant feature is used to refer to the entire kooky object, and thus to pick out the actual cause (or effect). This can be done, of course, because the irrelevant feature and the relevant feature are part of an accidental unity. ${ }^{7}$ For example, since the features of being a house builder and being a flute-player are both accidentally present in a particular man, to say that the flute-player built the house is true in the sense that the feature of being a flute-player is accidentally unified with the real cause-that of being a house builder. But since these two features are only accidentally unified, such a claim will fail to be fully explanatory, and will fail directly to pick out the cause in the unqualified sense of the house. ${ }^{8}$

\section{Túxๆ in the Eudemian Ethics}

If the $\tau \dot{x} \chi \eta$ of the penultimate chapter of the $E E$ is indeed the same thing as what Aristotle characterizes as túx $\chi$ in Physics ii 5, then we must show that this is so. We find evidence for this claim in passages such as $1247 \mathrm{~b} 9-15$, where Aristotle writes,

${ }_{5}$ Matthews 1982, 224. Matthews continues, 'Accidental unities exist, he supposes, but not in their own right; indeed it is, Aristotle says, only in an accidental sense of the verb "to be" that they can be said to be (Metaph. V1.2)'.

${ }^{6}$ Two points are relevant here. First, in the case of substances, the relevant feature may be being the substance itself. Second, here as elsewhere there is some temptation to translate $\alpha$ iría as something like 'explanation' rather than 'cause'. Here is not the place to enter into this interpretive debate. I think that (with minor modifications) my argument can be made to fit with any currently discussed interpretation of Aristotle's airiou.

${ }^{7}$ Matthews 1982 offers a compelling argument that this was in fact Aristotle's theory. There is no claim here that the theory of kooky objects is a tenable theory. On pp. 235-240, Matthews notes and considers some problems. One problem that is relevant to the present inquiry is that of precisely specifying the cause in the unqualified sense of an effect. For example, what is the efficient cause in the unqualified sense of the house? Is it the house-builder? Is it the flute-player? Is it Ariston? Is it some set of properties and substances such that Ariston and the property of being a house builder are both elements of the set?

${ }^{8} \mathrm{Cf}$. the schemata in Judson 1992, 80. This interpretation appears to be consonant with the interpretation of luck found in Lennox 1982, 227: 'What luck and spontaneity specifically lack, in each case, is any essential connection between source of change and product of change'. 
Since we see that some persons have been fortunate once, why not again [and again]? They would be repeatedly successful because of the same thing. For the same cause brings about the same effect. This, then, will not be from luck. But whenever the same thing should come from unbounded and indefinite

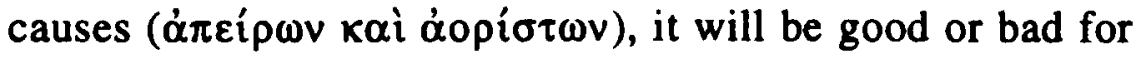
someone, but there will not be knowledge of it through experience, since some fortunate persons would have learned it, or all knowledge, as Socrates said, would be good fortune.

What is important at present to note about this passage is that at b12 Aristotle substitutes the expression 'unbounded and indefinite causes' for 'luck'. I take this to mean that he thinks that lucky causes are unbounded and indefinite. As I have argued, in the Physics Aristotle closely associates both these words with 'luck' (Phys. 196b25-26; 197a8, 9, 16-17, 20-21; see also Meta. 1065a32-34). The most telling evidence, however, will come from an analysis of the relevant parts of the chapter, to which I now turn.

The inquiry begins with a consideration of the three most likely reasons why a person might have good fortune: nature, wisdom, and the love of the gods. Aristotle initially rejects all three of these possible reasons. He argues that fortunate

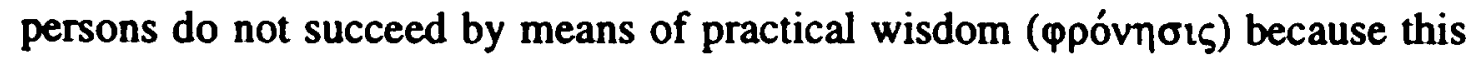
would imply that there is some sort of an account as to why fortunate persons are

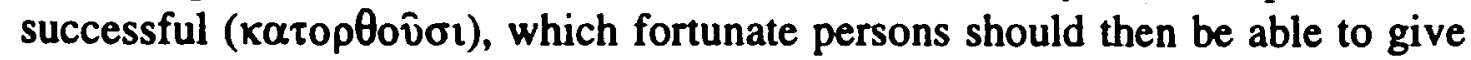

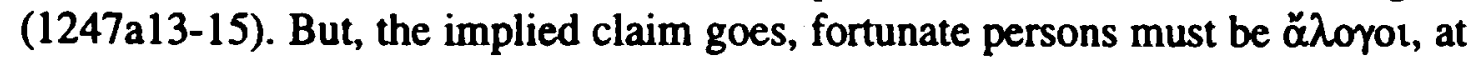
least with respect to why they have met with the success that makes them fortunate. Furthermore, he rejects the suggestion that the fortunate person is fortunate because of the love of a god, since it would be bizarre if the gods loved just any person and not the best and wisest ones (1247a28-29). Having rejected two of the three reasons why one might be fortunate, he notes that this means that the fortunate are so by nature ( $\varphi v ́ \sigma \varepsilon l, 1247$ a29-31). Aristotle immediately expresses some concern about this conclusion that good fortune must somehow be natural: 'But, indeed', he writes, 'nature is a cause of what occurs either always as it does or for the most part, but luck is just the opposite' (1247a31-33). He then goes on to fill out what he means by this claim.

If, then, there is an occurrence of something happening contrary to reason ( $\pi \alpha \rho \alpha \lambda \alpha^{\prime} \omega_{\varsigma}$ ), it seems that it would be part of luck. But if a person is fortunate on account of luck, the cause of this would not be of a certain sort, such as a cause which, when present, brings about its effect always or for the most part. Furthermore, if this person is successful or unsuccessful

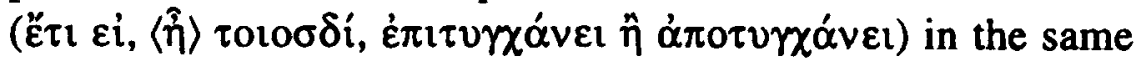
way that the blue-eyed person does not see well, then it is not luck that is the cause, but nature. So, then, such a person is not

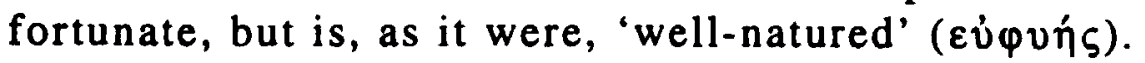
(1247a33-38) 
In this passage, Aristotle seems to be doing several things. First, he is reiterating the point that luck is not something that operates with a high degree of regularity. $\mathrm{He}$ is also reminding us that luck is contrary to reason ( $\pi \alpha \rho \alpha \lambda{ }^{\prime} \gamma \omega \varsigma, 1247 \mathrm{a} 33$ ). Finally, he makes a more substantial point when he says that one is not lucky as a result of one's natural constitution; rather, a person to whom good things happen because of his natural constitution should be called 'naturally well-endowed'. One reason that at this point in the dialectic Aristotle might want to make this

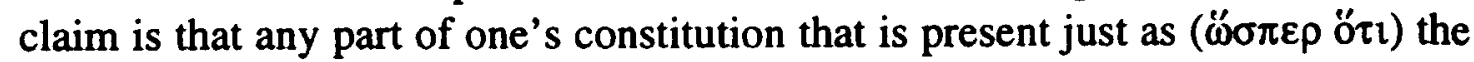
color of one's eyes is present would be so with great regularity. After all, the color of your eyes does not change from moment to moment. Furthermore, when the cause of good outcomes is a feature of one's constitution, there is not the crucial explanatory gap between the cause and the effect. ${ }^{9}$ Without this explanatory gap, the event might not be unaccountable, and so might not be appropriately said to be from luck.

Since Aristotle has already rejected all of the other possible sources of luck, when he rejects the view that a person's good fortune is the result of some natural feature of that person, he is led to ask whether there is such a thing as luck at all. Might we have been mistaken in calling certain people lucky? Could it not be the case that what appears to come from luck actually comes from something else? Aristotle, however, immediately rejects this suggestion. He says at 1247b2-3, 'But it is necessary for luck to exist and for it to be a cause'. As we have seen, it is possible to describe situations so that there is no apparent aitia: What makes it the case that the innkeeper cured the traveler's illness? A natural reply, for a

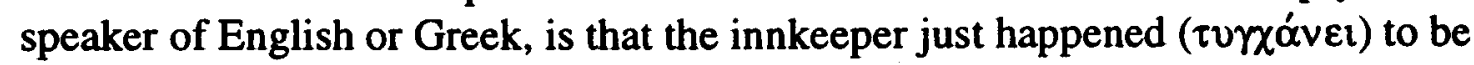
a doctor. Since it is always possible to describe a cause or effect so that only an accidental feature of the event is mentioned, such as when the innkeeper is said to be the cause of the traveler's recovery, and since such a description is all that is required for luck to exist, according to the account of luck in the Physics, Aristotle is justified in protesting that luck must exist and be a cause.

Immediately after saying that luck must exist and be a cause, though, Aristotle seems to allow that luck is, after all, theoretically dispensable (via elimination or reduction), which might seem to conflict with the strong claim he just made:

But if it is to be completely removed, and it is to be said that nothing comes into being from luck (but nonetheless we say that luck is the cause on account of not seeing the other \{true \}

${ }^{9}$ If we supposed that there was some feature of A's constitution that made him 'fortunate', then we could argue as follows:

(1) P has a natural constitution of type $F$.

(2) Persons with feature $F$ have good fortune.

(3) Hence, P has good fortune.

This argument shows how the supposition that some natural feature is responsible for good fortune would make it possible for good fortune to become rationally tractable: once the feature $F$ was identified, in theory we would be able to fix the extension of the fortunate persons. If $F$ is truly just a natural feature of the fortunate ones, then presumably its causal powers would be intelligible, too, and so good fortune would become-per impossible-rationally tractable. 
cause), then hence, when defining luck, people posit it as a cause which is inscrutable to human reasoning ( $\alpha \delta \eta \lambda$ ov $\dot{\alpha} v \theta \rho \omega \pi i v \omega \lambda \sigma \gamma \sigma \mu \hat{\varphi})$, with the result that [the real cause] has some sort of nature. This, then, should be another problem. $(1247 \mathrm{~b} 4-9)^{10}$

On my interpretation, there is no conflict here because this last passage is merely a short digression into the status of luck. Here Aristotle is making a point that concerns those people who say that nothing comes into being from luck in the way that things come into being as a result of the four 'real' causes (or whatever types of causes the objector countenances); instead these people say that when we call the cause of something luck, we mean only to say that the true cause or causes are unknown to us. Aristotle also points out that such a theory is committed to there being a genuine cause wherever there is a case of luck, and that this cause in the unqualified sense is what does the work that is attributed to luck. Thus, he is only pointing out what follows rather trivially from a certain view about the status of luck, a view that he remarks elsewhere is one that has been held by many ancient wise men (Physics 195b36-196a17).

Since Aristotle has defined luck as an accidental cause, it seems that his view accords with this ancient one, at least in outline. But, as he says, the correct analysis of luck, that is, whether luck is a true cause, is another problem than the one to be treated in an ethical work. This sentence (1247b8-9) indicates the end of his digression. Since it can be conceded that luck as an accidental cause is something that can be said to exist, even according to the ancient and influential view that would deny it any real status, the present ethical discussion in the $E E$ can proceed. Both those people who believe that luck is a genuine cause (like Aristotle's four, perhaps), and those who do not, can follow along with the ensuing ethical discussion. Aristotle's digression is a polite nod to those metaphysicians who-like Aristotle himself-deny that luck is an actual type of cause, with its own peculiar causal powers. By making this nod and then curtly saying that this

10 This passage is not easily translated and my translation opposes those of Woods and Kenny.

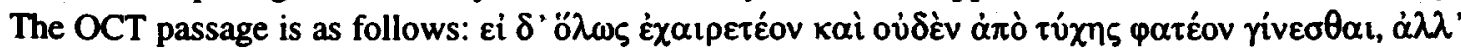

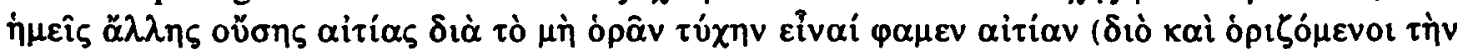

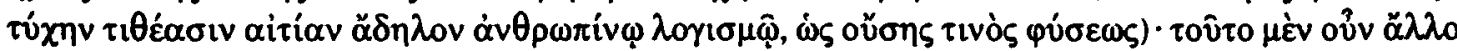

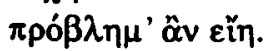

Here is how my translation works. (1) Removing the parentheses (following Bekker), I take the

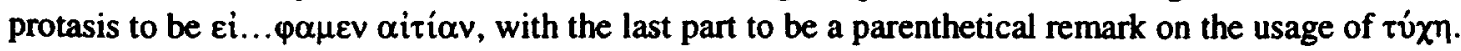

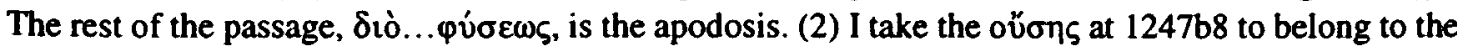

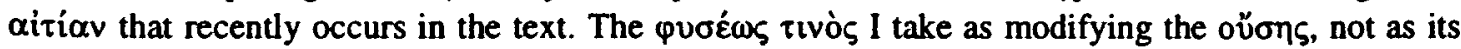
subject ('as though being of a certain nature'). If this last clause is translated in this way, it is possible

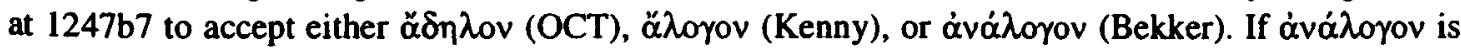
accepted, then Aristotle's point is that the position in question entails the additional claim that the true cause is one which we can (at least in principle) discover, and that it has a certain nature, some reliable and understandable way of operating, as opposed to the mysterious modus operandi of luck. Incidentally, I think that Shorey 1926 offers some good reasons for favoring $\alpha \tilde{\delta} \delta \eta \lambda_{0 v}$. However, even better confirmation of Shorey's thesis comes from the fact that when describing luck at Phys. 196b6

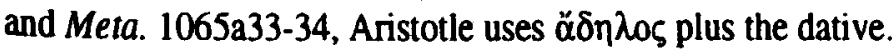


is a different issue from the present one, he is showing that the present argument will require only the most minimal metaphysical conception of luck, and that there is no place here for metaphysicians' objections concerning whether or not luck is a form of causation in the unqualified sense. It is not uncommon for Aristotle to refuse to allow his ethical discussions to become embroiled in metaphysical questions (e.g., $N E$ 1096b30-31, 1139b31-33, 1155b8-9, 1102a23-32, 1178a20-23; $E E$ 1217a2, 9-17). This tendency of Aristotle's is, I think, a product of his methodological beliefs about seeking no more and no less than the degree of clarity ( $\dot{\alpha} \kappa p 1 \beta \varepsilon i \alpha)$ appropriate to the sort of inquiry being undertaken (e.g., $N E$ 1094b24-27, 1098a26-33).

If these interpretations of the Physics and the $E E$ are correct, there is no need to suppose that $\tau \dot{x} \chi \eta$ is used in different senses in the Physics and $E E$, as Woods 1992 claims. The problem Woods sets up at $1247 \mathrm{~b} 1-9$, where Aristotle says that it is necessary for luck to exist and be a cause, can be avoided by appealing to the queer status of luck, that in one sense 'exists and is a cause', and in another sense does not exist and is not a cause. Luck does exist in the sense that there are events that can be described in such a way that there is a 'gap' produced by an accidental unity of some sort between cause and effect that needs to be filled in by positing luck as the aitia (e.g., a flute-player's building of a house). Luck does not exist as a fifth member of Aristotle's canonical list of types of causes. We can also see how the status of luck can be used to avoid another problem. Woods 1992, 167 argues that it is important for Aristotle to reject the position mentioned in 1247b4-8 - where luck is said to be posited only because the real cause is unclear to human reasoning-if he is to 'avoid the conclusion that there is no such thing as good fortune'. I have suggested that rather than rejecting this position, Aristotle embraces it, and can maintain that good fortune exists, simply because luck exists in the sense that the genesis of certain outcomes can be described in such a way that their true cause is not apparent. ${ }^{11}$ (Also, I will later argue that this problem is solved because Aristotle characterizes 'good fortune' in such a way that instances of it are no longer necessarily instances of luck.)

\section{Luck and Good Fortune in the Eudemian Ethics}

Before turning to the discussion of good fortune, 12 it will be useful to digress briefly, and, turn to the opening lines of this chapter to consider why Aristotle is concerned with good fortune at all. What motivates Aristotle's discussion of the nature of good fortune is his concern with the nature of happiness, which he men-

11 At least for those cases for which there is a true cause: for cases such as when a fancy-cook just happens to make something healthful, there is no non-accidental efficient cause of the healthy food.

12 Although Aristotle runs his argument using the fortunate person, in the beginning of the chapter, he states his thesis as whether or not the fortunate person and unfortunate person are so by nature (1247a2-3). Furthermore, at several places throughout the chapter, he mentions bad fortune or the unfortunate person: 1247a13, a36, and b38. Thus, it seems important to remember that Aristotle's

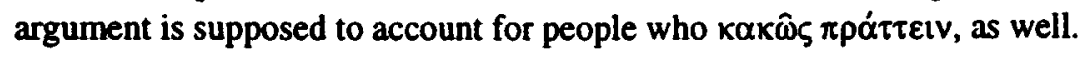


tions at the beginning of the chapter (1246b37-1247a3): 'not only do practical wisdom and virtue make happiness ( $\varepsilon \dot{\pi} \pi \rho \alpha \gamma^{\prime} \alpha$ ), but we also say that the fortunate

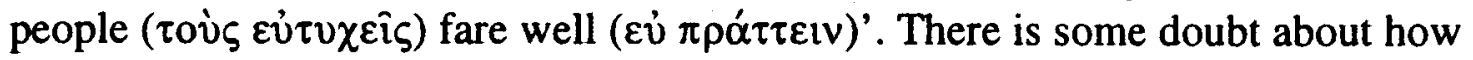

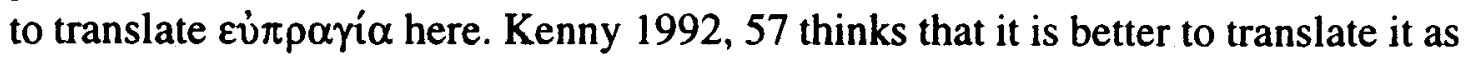
'well-doing' rather than 'happiness'. He writes,

I take the word to mean the actions which a virtuous person does. It is common ground, in both the $N E(1105 b 5-9)$ and in the $E E$, that one can do the acts of a virtuous person without being virtuous. Despite a weight of scholarly opinion, I do not think that eupragia in this context can mean anything like eudaimonia. Neither in the $N E$ nor in the $E E$ would Aristotle have agreed that true happiness could come about by mere luck.

This passage makes two separate points: (a) It is not reasonable to take this occurrence of $\varepsilon \dot{u} \pi \rho \alpha \gamma i \alpha$ to mean $\varepsilon \dot{\delta} \delta \alpha \iota \mu$ oví $\alpha$, because there is no evidence that suggests that Aristotle would agree that luck can bring about happiness; and (b) It is reasonable to take $\varepsilon \dot{\pi} \pi \rho \alpha$ í $\alpha$ to mean merely those actions a virtuous person

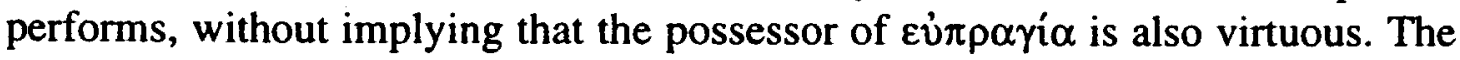
defense of (b) is that Aristotle makes a distinction between being a virtuous person and (merely) doing the actions of a virtuous person. But in reply to points (a) and (b), I claim that there are several reasons why we can take Aristotle to mean happiness by this use of $\varepsilon \dot{u} \pi \rho \alpha \gamma i \alpha$. First, it is possible to take $\varepsilon \dot{\pi} \pi \rho \alpha \gamma^{\prime} \alpha$ here to

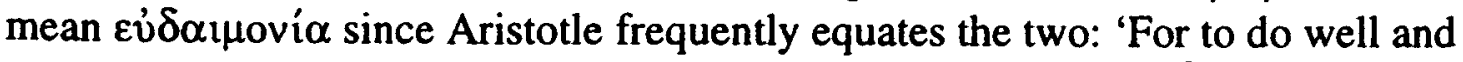

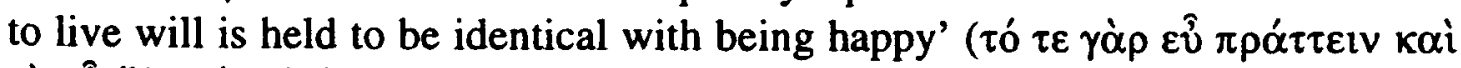

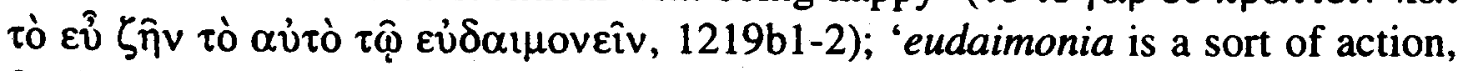
for it is eupraxia' (Phys. ii 6.197b4-5; NE 1095a 18-20, 1098b20-22). ${ }^{13}$ So it seems that Kenny will need to give some further reason to think that this occurrence of $\varepsilon \dot{\pi} \pi \rho \alpha \gamma i \alpha$ ought to be taken to mean acting well, and not happiness. Second, in $E E$ i 1, Aristotle thus states his program:

But first it is necessary to consider what living well ( consists in, and how it is to be acquired, whether those who get

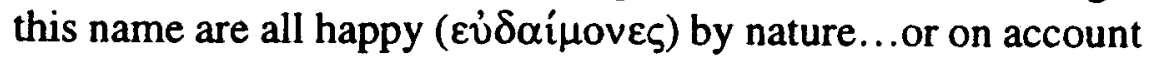
of education...or on account of some sort of training...or by none of these ways, but either-exactly like the nymph-possessed or the god-possessed persons-by the influence of some divine being, just as if they were inspired, or on account of luck

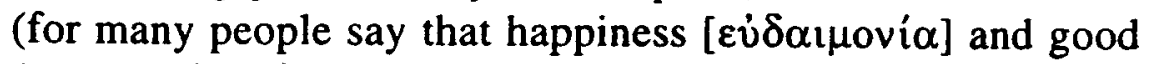

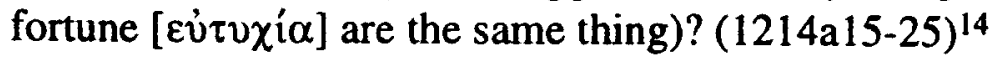

${ }^{13}$ In support of Kenny, see 1139b3-4 and 1140b7, where, when Aristotle says that $\varepsilon \dot{\pi} \pi \alpha \xi^{\text {i } \alpha}$ is an end ( $\tau \varepsilon \dot{\lambda} \gamma_{0}$ ) the context makes it clear that he is talking about good action (as opposed to good pro-

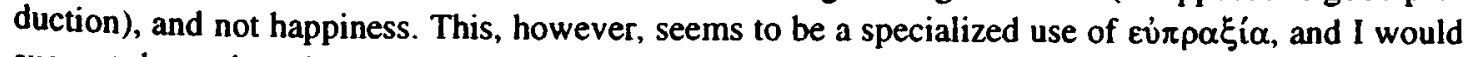
suggest that unless there is strong contextual evidence otherwise, as there does not seem to be at $E E$

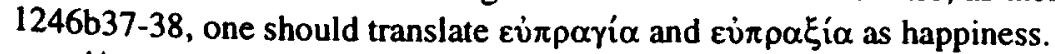

${ }^{14}$ Kenny 1992, 4 himself notes this passage. 
Aristotle seems to think that it is an important question whether we become happy as a result of divine influence or luck, ${ }^{15}$ and in the passage I have quoted he does promise to discuss the topic. Since he later turns to a discussion of the influence of luck and the divine, and introduces this discussion by saying that

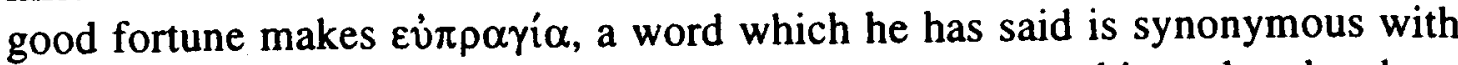

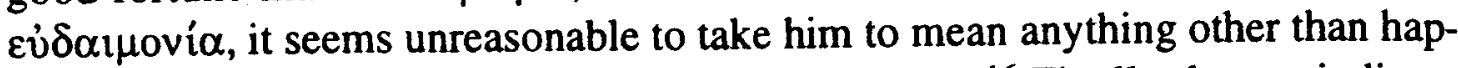
piness by his use of this word in the present context. ${ }^{16}$ Finally, let me indicate how I wish to address point (a). Although it is true that Aristotle did not think that happiness could come about by mere luck, I shall argue that in this chapter of the

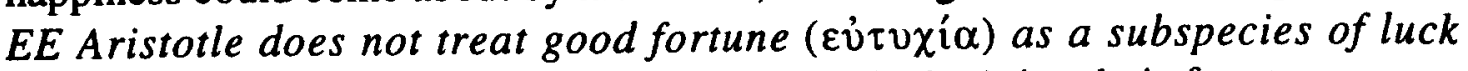
( $\tau \dot{\chi} \chi \eta$ ). Since good fortune is not just a kind of luck, Aristotle is free to argueand does argue (so I claim) - that some people are happy by means of good fortune. If I am right that for Aristotle the sort of good fortune he is concerned with here is not a form of luck, then point (a) becomes an irrelevant objection, and thus loses all force. With these points in mind, we may now turn back to our analysis of the target chapter of the Eudemian Ethics.

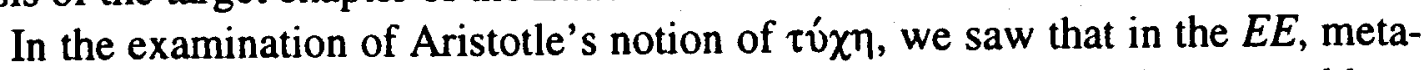
physical questions about luck are dismissed as being another (different) problem. Aristotle then raises the question why those who have had good fortune

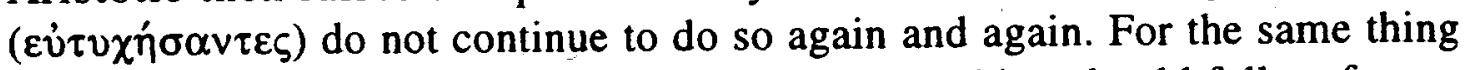
should come from the same cause. But if the same thing should follow from a number of unbounded and indefinite causes, that thing could be good or bad for a person - and thus constitute good or bad fortune-but it would be impossible to have knowledge ( $\left(\dot{\pi} \pi_{1} \sigma \tau \dot{\imath} \mu \eta\right.$ ) of its causes (cf. Meta. vi 2.1026b2-5, 1027a20). It is important to see that the possibility of knowledge is ruled out, because otherwise some fortunate people might have learned to be fortunate, or perhaps we would have to say that all bits of knowledge are instances of good fortune, both of which options are absurd (1247b9-18).

How should we understand this claim? Kenny suggests that we view this as an elaboration on the previous passage, which concluded that whether or not luck is merely a cloak for hidden causes is a separate problem from the present one. He suggests that we take $1247 \mathrm{~b} 9-18$ as showing that if luck was merely a cloak for hidden causes, inconsistencies result. On the one hand, Kenny 1992, 65 writes, 'If there was a single hidden cause, there would be regularity in the effect (which is inconsistent with the outcome being a matter of luck), and there would be a

15 E.g., $N E$ 1095b32-1096a2, 1099a32ff., 1100b22ff., 1124a14, 1153b16, 1171a21-b28; $E E$ 1214a23-26; MM 1206b30-1207b18, 1323a25; Po. 1323a38, 1331b4l; Rh. 136lb39-1362all, 1390a29-1391b3.

16 There is a line of support that Kenny does not take advantage of, that would support his interpretation. It is that throughout the present chapter of the $E E$, Aristotle consistently talks about the for-

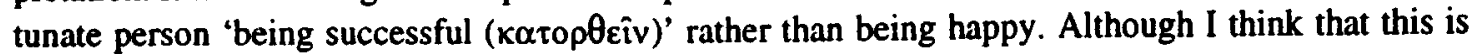
explicable on my interpretation, because there are some forms of good fortune that would not be especially conducive to happiness, I think this feature of the chapter might also be interpreted so as to provide support for Kenny's interpretation. 
theoretical science of the cause-effect relationship (which is inconsistent with the hypothesis that the cause is opaque to reason)'. On the other hand, if luck is a cloak not for one cause but for 'multiple indeterminate causes, then indeed there could be no theoretical science; but there could be an empirical science. But there is no such science'. There is no such science, Kenny argues, because if there were, then some fortunate people would have learned it, which is absurd unless we suppose that science and luck somehow coincide.

If Kenny's interpretation is adopted, then Aristotle must be arguing at 1247b915 that luck cannot be a cloak for hidden causes; yet if Aristotle is claiming that luck cannot be a cloak for hidden causes, then he also seems committed to the claim that luck is a real cause, as opposed to being merely a cloak. However, as I have suggested, Aristotle's statement at $1247 \mathrm{~b} 2-3$ - where he says that it is necessary for luck to exist and for it to be a cause-does not imply the conclusion that luck is a real, fifth, cause. Instead Aristotle makes this strong statement at b2-3 precisely because he himself believes that in some sense luck is a cloak for hidden real causes, and that his present argument does not rest on a realist conception of luck (but his argument in the $E E$ is designed to be acceptable even to those who hold such a view). Hence it is not necessary to look for an interpretation of this passage that implies that luck is a real cause. (Incidentally, Aristotle also remarks at Meta. 1027a10-11 that the accidental must exist. But for reasons parallel to the ones just given, this claim does not conflict with other claims he makes in the very same chapter of the Metaphysics, to the effect that the accidental is almost only a name [1026b13-14], and that the accidental is similar to nonbeing [1026b21].) One of my central claims is that there is strong textual evidence to link rú $\chi$ in this part of the EE with the Physics (and Metaphysics). ${ }^{17}$ Yet Kenny must assume that $\tau$ vó $\eta$ is used equivocally in these texts, since in the Physics and Metaphysics, Aristotle explicitly denies that luck is a genuine form

${ }^{17}$ I have argued that there is even evidence for the consistency between the $E E$ and the Physics in the very passage that Kenny takes to be a two-part reductio against the sort of position Aristotle holds in the Physics: Aristotle describes the lucky outcome as being from 'unbounded and indefinite' causes (1247b12).

It might be thought that I am being inconsistent because I am objecting to Kenny's interpretation on the grounds that it does not accord with the notion of luck in the Physics, and yet I am also sug.

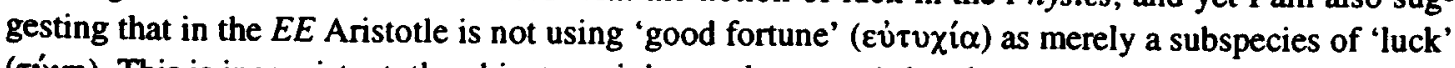
$(\tau v ́ x \eta$ ). This is inconsistent, the objector might say, because Aristotle concludes his discussion of luck in the Physics with a short discussion of good fortune (197a25-32; cf. Meta. 1065a35-b1). In this pas-

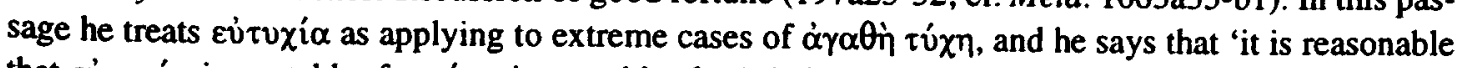

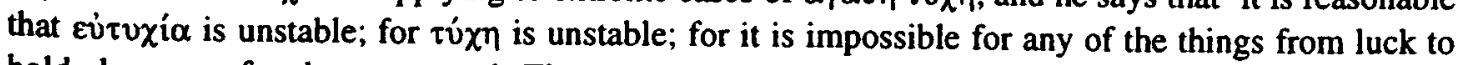
hold always or for the most part'. There are a number of replies to this objection. (1) If anything comes through clearly in this part of the $E E$, it is that Aristotle is breaking new philosophical ground. Throughout this chapter the inquiry seems to have an exploratory tone, and the way that Aristotle wrestles with the endoxa about luck and good fortune suggests that this new investigation might be forcing him to be willing to modify some of his earlier beliefs. (2) My interpretation does not deny that cases of good luck are cases of good fortune; but, as Aristotle suggests, 'good fortune' is used in many ways. I am arguing that one of the ways 'good fortune' is used is to pick out certain cases which do not appear to be simply cases of luck. 
of causation, and in the $E E$, on Kenny's interpretation, Aristotle explicitly declares that luck is a genuine form of causation. Since my interpretation makes Aristotle's use of $\tau \dot{x} \chi \eta$ univocal throughout the EE, Physics, and Metaphysics, and Kenny's does not, ceteris paribus, my interpretation is to be preferred. ${ }^{18}$

Finally, Kenny's argument depends on the following counterfactual conditional statement,

(I) If luck were a cloak for multiple indeterminate causes, then there could be an empirical science of the cause-effect relationship of 'lucky' events. ${ }^{19}$

The context of $1247 \mathrm{~b} 9-18$ makes it clear that the multiple indeterminate causes all bring about the same thing. The context also suggests that this 'same thing' is

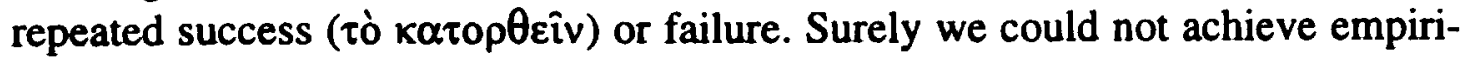

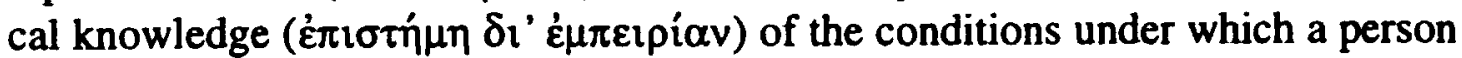
experiences continued success in the various arenas of daily life-how he just happens to make the right decision in court, just happens to come across enough money for an act of magnanimity, just happens to develop a brilliant and successful military strategy, etc. But even if that same thing is something as definite as, say, maintaining sufficient wealth, the conditional still does not hold. For Andron's inheriting money from his uncle maintained his wealth; but so did Andron's happening upon someone who owed him money, and so on. ${ }^{20}$ This story about Andron could be extended in obvious ways, and it should be clear that there could be no empirical science of the cause-effect relationship with the effect being Andron's maintaining sufficient wealth. ${ }^{21}$ If this argument is right, then Aristotle would have no reason to accept a conditional like (I). ${ }^{22}$

18 Hence, he will need to provide interpretations of passages such as 1247a31-35, b1, b12, and 1248a9-10 which will make room for one reasonably to charge Aristotle with equivocation.

19 On p. 65, as part of his reconstruction of the argument at 1247b9-18, Kenny writes, 'If lucky outcomes are the effects of multiple indeterminate causes, then indeed there could be no theoretical science; but there could be an empirical science'.

20 Note that at this point in the text, Aristotle's discussion comports neatly with the interpretation of accidental causation depending on kooky objects or events. In fact, it seems that this interpretation of accidental causation must be incompatible with (I). For if continued luck of one sort necessarily involved a series of instances of accidental causation, then it is hard to see how (I) could be true. After all, if there is no intellectually principled way to understand how the single case of going to the market for oranges caused one to recover a debt, when the two events are described in just this way, a long series of causal event-pairs of this type would be no more intelligible than the single case-in fact, such a series would be even harder to understand.

21 The story can be extended so that the only causal statements it generates would be (a) statements with a long -or even infinite-disjunction of otherwise unrelated events followed by 'cause Andron to maintain sufficient wealth'; and (b) statements like: 'Whatever causes Andron to maintain sufficient wealth causes Andron to maintain sufficient wealth'.

22 The proper reconstruction of this passage seems to me to be as follows.

(i) If there is empirical knowledge of what comes from multiple indeterminate causes, then some people will have learned to be fortunate, or all knowledge will be good fortune (1247b14-15).

(ii) People cannot leam to be fortunate, and it is not the case that all knowledge is good fortune.

(iii) <from (i), (ii) > It is not the case that there is knowledge of what comes from multiple indeterminate causes. 
At this stage of the investigation, Aristotle has considered the three most likely explanations of good fortune (nature, intelligence, and the concern of a god), and has rejected them all as suitable explanations. The only apparent remaining explanation of the fortunate person is that he is one to whom good things happen often and with little or no interruption, not because of the sort of person he is, but for the same reason that one might have a successful run at throwing dice $(1247 \mathrm{~b} 15-18)$. Aristotle clearly intends dice-throwing to be a type of activity that is controlled by luck (cf. 1247a21-23). If he thought that good fortune was merely a narrow form of luck, then it would seem that he should be at the end of his investigation. But he is not. In fact, Aristotle turns to a further consideration of the well-natured person, which suggests that the account of the fortunate person as being fortunate by means of luck is not a satisfactory solution. ${ }^{23}$ Furthermore, if the occurrences of $\varepsilon \dot{v} \pi \rho \alpha \gamma i \alpha$ at the beginning of the chapter are supposed to mean $\varepsilon \dot{\delta} \delta \alpha \iota \mu$ ovi $\alpha$, then there is a principled reason why Aristotle must be unsatisfied with this account of good fortune. Eudaimonia is, among other things, an activity of the soul in accordance with perfect virtue (e.g., 1219a37-38; cf. $N E$ 1098a16-18). Virtue, inter alia, is a disposition to make choices and act in the right ways (1219a33-34; cf. $N E$ 1106b36-1107a2). If eudaimonia entails virtue, and virtue entails certain dispositions, then a person cannot be eudaimon unless he has certain dispositions. So, for a person to have eudaimonia by means of good fortune, the good fortune will have to be responsible for the person's activity of the soul in accordance with perfect virtue. That is, the good fortune will have to be the cause of the person's acquiring certain dispositions. Thus it is unsurprising that when Aristotle returns to a discussion of the well-natured person, it is in terms of the impulses in the soul.

Aristotle begins his second consideration of the well-natured person by comparing well-natured people to people who can sing well, and yet do not have for-

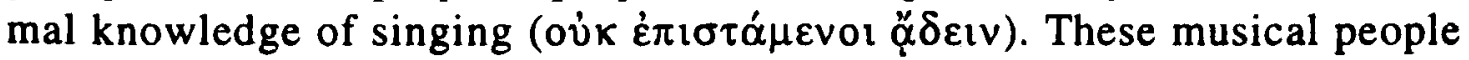
cannot explain why or how they do what they do, they just automatically sing in the right way. In the same manner, well-natured persons do not have a reason

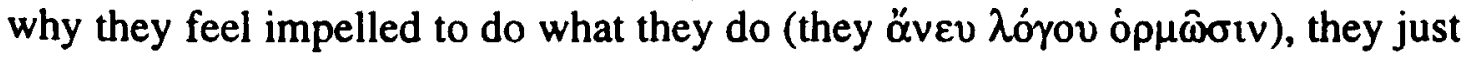
do desire the right thing at the right time and in the right way. The result is that these persons are successful, whether or not they happen to be stupid and irrational.

After this description of the well-natured person, Aristotle insists on a general condition for being a fortunate person: 'Those persons are fortunate who, without reason, succeed for the most part' $(1247 \mathrm{~b} 27-28) .{ }^{24}$ The well-natured person

(iv) <from (iii)> If the same thing comes from multiple indeterminate causes, then there will not be empirical knowledge of it (1247b12-14).

${ }^{23}$ Aristotle's displeasure with the idea that good fortune comes only from luck seems to show up in the way he starts the next section: 'What, then? ( $\tau \dot{i} \delta \dot{\varepsilon} \delta \dot{\eta} ;$ ) Aren't there impulses in the soul, some from reckoning, and some from irrational desire?' (1247b /8-19).

${ }^{24}$ The passage at $1247 \mathrm{~b} 26-28$ appears to be at least a sufficient condition; in the light of $1248 \mathrm{~b} 3$ 7 , it cannot be a necessary condition. 
clearly falls under this condition, and Aristotle concludes, 'There could, then, be persons who are fortunate by nature' (1247b28). This general condition for being a fortunate person is, I think, important. It shows that the kind of good fortune Aristotle is interested in is long-term good fortune, that holds 'for the most part' (cf. 1246b37-38). Thus, the likelihood of there being persons who are fortunate because of luck in this sense of 'fortunate' is about the same as the likelihood of someone rolling dice throughout his life and rolling nothing but sixes. Furthermore, such good fortune would be a case of luck holding for the most part, something which, by its definition, it cannot do (EE 1247a31-35, Phys. 196b10-12, Meta. 1065a30-31, 1065a1-5).

So far Aristotle's inquiry has produced the following two claims: (1) fortunate persons have fairly long-term, continuous success, and (2) luck does not produce long-term, continuous success. Aristotle avoids this apparent problem by making a characteristic move: he suggests that 'good fortune' might be used in several

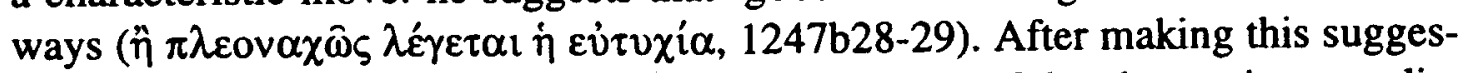
tion, he explores how this might be so; the remainder of the chapter is spent discussing the various kinds of good fortune. ${ }^{25}$

Aristotle considers cases in which the agent is wildly successful after having reasoned badly, or after having aimed to achieve something other than the good, or less of the good than was available to him. It is possible, Aristotle suggests, that such persons are fortunate on account of nature. Their good fortune would be due to nature if what made them successful was an impulse (o $\rho \mu \eta \dot{)}$ or desire (őp\& $\xi_{1 \varsigma}$ ) for the right thing (1247b34-37). An example of such a case would be the person who reasons badly to the conclusion that he can help his city by setting its weapons on fire. Just when he is aiming the flaming arrow at the city's catapult, he is suddenly overcome by a desire to shoot the enemy's catapult. This desire overrides the impulse from his reasoning, and as a result of it, he saves the city. ${ }^{26}$ Although Aristotle says nothing explicitly, his statement that it is possible for people to be fortunate despite their bad reasoning, 1247b33-34 suggests that there is a contrasting case in which a person's good fortune despite his bad reasoning is not due to his nature. An example of this type of good fortune would be the person who reasons badly that he can help his sick father by feeding him turpentine. Unbeknownst to the person, someone had put healthful medicine in the turpentine jar, and so he ends up curing his father. In this case, the good fortune seems to be due not to any part of the agent-such as his desires, beliefs, intentions, or reasoning - but to certain external features of the world, namely, there

25 It might be helpful to give an explicit (but rough) definition of 'natural' good fortune. By 'nat-

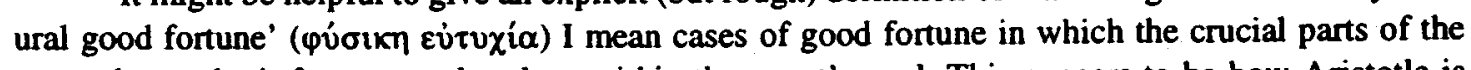
event that make it fortunate take place within the agent's soul. This appears to be how Aristotle is thinking of good fortune caused by nature in the later parts of this chapter of the $E E$ (from 1247b18 onward).

${ }^{26}$ On the conditions for virtue, and whether this would constitute a virtuous action, see Burnyeat 1980. Also, White 1992 makes much of this kind of good fortune, and argues that it is connected with the phenomenon of natural virtue that Aristotle discussses at $N E$ vi 13. 
being medicine in the turpentine jar. Both of these two types of good fortune are going to be episodic. This is so obvious in the latter type of case that Aristotle does not mention it. The next time the person tries to cure someone with turpentine, he will probably not be so lucky as to end up feeding him medicine. Aristotle does say outright that the former type of good fortune will be episodic: after experiencing success as a result of letting his impulses guide his actions, the person may try following his desires and be unlucky (1247b37-38). Aristotle appears to consider cases of natural good fortune such as the person who shoots the enemy's catapult as being to a limited extent caused by nature and 'not altogether without an account' (1248a7-8). ${ }^{27}$ Because such cases in which the agent's impulses cause the good fortune are not completely irrational, they are not due to luck, but only seem to be (1248a11). It was not luck that caused the person to shoot the enemy's catapult instead of the city's, but rather his lastminute overriding impulse. ${ }^{28}$

So far, three of the four types of good fortune have been discussed. The first kind, continuous external good fortune, which would be like throwing sixes throughout one's life, has been set aside by Aristotle as too improbable to merit further consideration. ${ }^{29}$ Aristotle treats the second and third kinds-episodic external good fortune (cases like the one in which there was medicine in the turpentine jar) and episodic natural good fortune (cases like the person who impulsively shoots the enemy's catapult) - as kinds of good fortune that actually obtain. He then prepares the way for the final kind of good fortune, continuous natural good fortune, by asking from where the initial impulses or desires that are

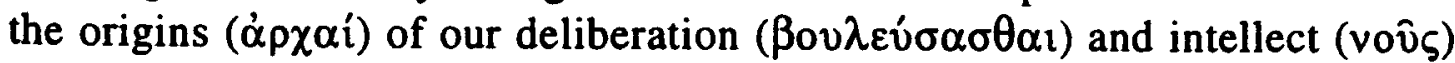
come. There cannot be intellect prior to intellect and deliberation prior to deliberation, on pain of an infinite regress (1248a18-22). ${ }^{30}$ But if what our deliberation and intellect are founded upon is something due to luck, then all our deliberation and intellect is due to luck, and so everything we do and think is due to luck, and the point of the present inquiry is lost because at bottom everything that people

27 When Aristotle says that these cases are not altogether without an account, what he is suggesting is, I think, that the sort of cases he has in mind are ones that might be explained by saying that the agent acted according to some unexpected overriding impulse that might have resulted from his sometimes undisplayed good sense or practical wisdom. I think that the sort of case Aristotle is trying to pick out here is the sort that might stimulate us to say something like 'Although he had reasoned it out that burning the city's weapons would be for the best, deep down inside he knew that this could not be the right thing to do'.

28 This interpretation is supported by the conclusion of this section (1248a12-16): 'Thus, this argument does not show that good fortune is due to luck, but that not all who seem to be fortunate are successful because of luck, but rather they are successful because of nature; nor does it show that luck is the cause of nothing, but that it is not the cause of all that it seems to be'.

${ }^{29} \mathrm{By}$ 'external good fortune' I mean good fortune that is not natural good fortune, i.e., good fortune whose relevant cause is not an agent's internal impulse.

${ }^{30}$ See also Post. An. i 3. Aristotle appears to be using voûs and its forms in a loose sense, as (I think) he often does. He does not appear to be using the term in its stricter sense of Post. An. ii 19 and NE vi 6. 
do is due to luck. ${ }^{31}$ Thus, Aristotle is led to ask, 'What is the origin of motion

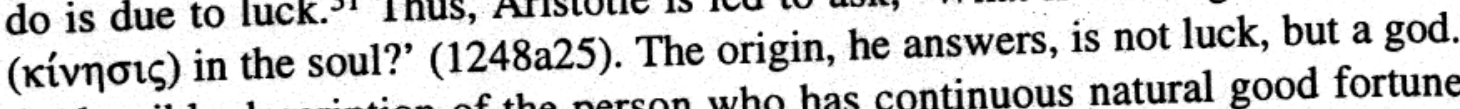
A plausible description of the person who has continuous natural good fortune can now be given. It is important that Aristotle make such a kind of good fortune plausible, because as was noted earlier, at $1247 \mathrm{~b} 26-28$ he indicates that there are fortunate people whose good fortune is continuous, not episodic. Also, if my argument above is correct, and Aristotle is claiming that good fortune causes some people to be happy, then there will have to be a continuous form of natural good fortune to bring this about. The only other option for continuous good fortune-the external, dice-throwing kind-has been dismissed. Aristotle's account of the continually naturally fortunate person is, then, as follows. While the origin of motion in the soul is god, what distinguishes people with continuous natural good fortune is that the divine part in them (which is greater than knowledge or intellect) dominates their lives. Thus, being irrational, when they have an impulse

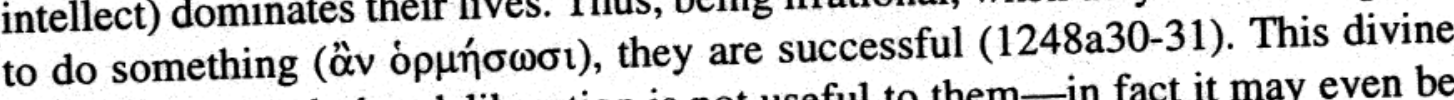
inspiration is such that deliberation is not useful to them-in fact it may even be better if they are not good at rational activity - because their prophetic abilities are swifter than the deliberations of the phronimoi and the sophoi ${ }^{32}$ Thus, such persons will succeed throughout their lives, because their impulses come directly from god (or from their divine parts).

Aristotle concludes his discussion of good fortune by saying

It is apparent, therefore, that there are two forms of good fortune. The one kind is divine (and hence the fortunate person seems to be successful on account of a god); such a person is one who is likely to be successful in accordance with his impulses. The other sort of person is successful contrary to his impulse. Both of these kinds of fortunate persons are irrational; the first kind of good fortune is more continuous than the latter, which is not continuous (1248b3-7).

In his conclusion it seems that Aristotle is making his main distinction between continuous and episodic good fortune. The only kind of continuous good fortune worth discussing is continuous natural good fortune, but there are two kinds of sporadic good fortune, natural and external, and he seems to lump these together.

${ }^{31}$ In such a case, I take it that any interesting distinction between external and natural good fortune would be lost, and the only type of good fortune remaining would be the kind purely due to luck. 32 I am following Kenny's translation of 1248a34-35. He emends the passage from the OCT's

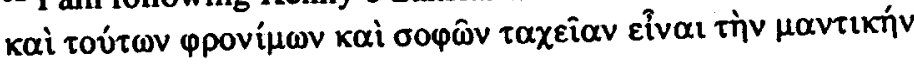

to

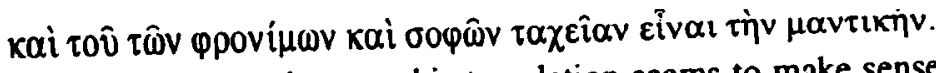

I am following Kenny, because his translation seems to make sense out of this passage. Taken by itself, it seems to say that the prophecy of the phronimoi and the sophoi is swift. This, however, seems to make no sense in the context. Liddell and Scott give no suggestion as to how to make $\tau \alpha \chi \varepsilon i \alpha v$ into a comparative adjective. 
Both kinds of episodic good fortune are contrary to impulse: in the case of natural good fortune, the person acted contrary to his impulse from reasoning (1247b18-19), and shot the enemy's catapult; in the case of external good fortune, the good fortune was contrary to the person's impulse to feed his father turpentine. ${ }^{33}$

\section{Conclusion}

I have attempted to establish two points. First, I have argued that $\tau$ iv $\chi \eta$ is used in the $E E$ in the same way as it is used in the Physics. I have shown that there is textual evidence for this claim, and that its apparent problems can be overcome by a proper understanding of $\tau \dot{x} \chi \eta$. Second, I have contended that in the $E E$, Aristotle argues that $\varepsilon \dot{\tau} \tau v \chi i \alpha$ is not necessarily a kind of $\tau \dot{v} \chi \eta$. To this end, I have presented an interpretation that accommodates this claim and that makes sense out of certain difficult parts of the text. Furthermore, I have responded to Kenny's interpretation, that opposes the distinction I draw between luck and good fortune.

Rather than presenting all my arguments against Kenny's interpretation, particularly with respect to the second half of this chapter of the $E E$, I simply present my interpretation as an alternative. Kenny 1992, 74-75 argues that the wellnatured individual is a separate candidate for being fortunate from the divinely inspired person, and that the divinely inspired form of good fortune 'is only doubtfully worthy of the name, since irregularity is taken by Aristotle as one of characteristics of luck'. I counter that the divinely inspired persons form an important kind of fortunate person, because they are needed to explain the fact that there are fortunate persons who, without having a $\lambda$ óyos, are successful for the most part (1247a34-35). Moreover, I have argued that Aristotle refines what he means for a person to be fortunate 'by nature', so that this account actually includes that of the person who is fortunate by means of a god. If my interpretation is correct, then it would seem that Aristotle has not completely dismissed any of the three reputable opinions $(\varepsilon / v \delta o \xi \alpha)$ about good fortune: that it is caused by (1) nature, (2) intelligence, or (3) a god. Good fortune can be caused by nature, because what makes the fortunate person fare well is the impulses from within him, that is, from his nature. (2) seems to be saved in a limited sense, since the prophetic capacity of the divinely inspired person replaces his intellectual capacities, doing similar work for him that the intellectual capacities do for other persons. (3) is shown to be true, too, since the divinely inspired person receives his inspiration from a god. Thus, my interpretation seems to accord with Aristotle's general method in ethics (see, e.g., $N E$ 1145b2-7), which should constitute

${ }^{33}$ Much more could be said on the relation between Aristotle's discussion of good fortune and contemporary discussions of moral luck. The current debate is centered around Williams 1976 and Nagel 1979. In particular, it should be noted that Williams finds the distinction between intrinsic and extrinsic luck to be morally significant (121). This distinction is similar to Aristotle's distinction between what 1 have called natural and external good fortune. 
evidence in its favor. ${ }^{34}$

Department of Philosophy

Rutgers University

New Brunswick NJ 08903

\section{BIBLIOGRAPHY}

Barnes, J. 1980. 'Aristotle and the Methods of Ethics' Revue internationale de philosophie 34: 490511.

Barnes, J. ed. 1984. The Complete Works of Aristotle. The Revised Oxford Translation. Princeton: Princeton University Press.

Burnyeat, M.F. 1980. 'Aristotle on Learning to Be Good' 69-92 in A.O. Rorty ed. Essays on Aristotle's Ethics. Berkeley: University of California Press.

Charlton, W. 1970. Aristotle's Physics, Books I and II. Oxford: Clarendon Press.

Freeland, C.A. 1992. 'Accidental Causes and Real Explanations' 49-72 in L. Judson ed. Essays on Aristotle's Physics. Oxford: Oxford University Press.

Irwin, T. 1981. 'Aristotle's Methods of Ethics' 193-223 in D.J. O'Meara ed. Studies in Aristotle. vol. 9. Studies in Philosophy and the History of Philosophy. Washington, DC: The Catholic University of America Press.

Judson, L. 1992. 'Chance and "Always or For the Most Part" 73-99 in Aristotle' in L. Judson ed. Essays on Aristotle's Physics. Oxford: Oxford University Press.

Kenny, A. 1992. Aristotle on the Perfect Life. Oxford: Clarendon Press.

Lennox, J. 1982. 'Teleology, Chance, and Aristotle's Theory of Spontaneous Generation' Journal of the History of Philosophy 20: 219-238.

Matthews, G.B. 1982. 'Accidental Unities' 223-240 in M. Schofield and M.C. Nussbaum edd. Language and Logos. Cambridge: Cambridge University Press.

Mills, M.J. 1981. 'Eudemian Ethics $\Theta$, 2, 1247a7-13' Hermes 109: 253-256.

Mills, M.J. 1983. 'Aristotle's Dichotomy of 'Evtuxía (Eudemian Ethics $\Theta, 2,1247 \mathrm{~b} 18-1248 \mathrm{al5}$ )' Hermes 111: 282-295.

Nagel, T. 1979. 'Moral Luck' 24-38 in Mortal Questions. Cambridge: Cambridge University Press.

Pakaluk, M. 1992. 'Commentary on White' 169-180 in J. Cleary ed. Proceedings of the Boston Area Colloquium in Ancient Philosophy vol. 8. New York: University Press of America.

Pritzl, K. 1994. 'Opinions and Appearances: Endoxa in Aristotle' Ancient Philosophy 14: 41-50.

Reeve, C.D.C. 1992. Practices of Reason. Oxford: Clarendon Press.

Roche, T. 1988. 'On the Alleged Metaphysical Foundation of Aristotle's Ethics' Ancient Philosophy 8: 49-62.

Shorey, P. 1926. 'Note on the Eudemian Ethics, 1247b6' Classical Philology 21: 80-81.

White, S.A. 1992. 'Natural Virtue and Perfect Virtue in Aristotle' 135-168 in J. Cleary ed. Proceedings of the Boston Area Colloquium in Ancient Philosophy vol. 8. New York: University Press of America.

Williams, B. 1976. 'Moral Luck' Proceedings of the Aristotelian Society Supp. vol. 50: 115-135.

Woods, M. 1992. Translation of and Commentary on Eudemian Ethics. Oxford: Clarendon Press. 